\title{
Estimate the Ventilation Effect from Wire Mesh Screen Assisted Solar Chimney
}

\author{
Md. Mizanur Rahman, Mohd. Suffian Bin Misaran, Mohd. Jamrye Bin Jamanun and Ahmed Jawad \\ Faculty of Engineering, Universiti Malaysia Sabah, Kota Kinabalu, Sabah 88400, Malaysia
}

\begin{abstract}
In 1750s European houses, chimneys are used to remove smoke and dust particle from the fire place to the ambient. At present the applications of chimneys are extended for house ventilation, which is known as solar chimney assisted ventilation system. In this paper, the effect of wire mesh screen on chimney assisted ventilation system is studied and presented. Natural draft chimney integrated with solar heating system that is known as solar chimney, can be used for building ventilation. Number of research works had been conducted on different types of solar chimney to enhance the building ventilation performance. In this study a solar chimney model is designed and modified with wire mesh screens. An electric heating system is installed in the models to replace the solar absorber in the solar chimney. The airflow rates and the exit air temperatures are also measured and compared for normal chimney and modified chimneys under different heat loads. The performances of the chimneys are evaluated to determine the effects of wire mesh screen on the solar chimney. Experimental results indicated the solar chimney model with $0.64 \mathrm{~mm} \times 0.64 \mathrm{~mm}$ pore size wire mesh screen at the exit is able to enhance velocity and the exit air temperature are about $54 \%$ and $41 \%$, respectively. It has been concluded that the wire mesh screen has significant effect of model solar chimney and is able to enhance the performance.
\end{abstract}

Key words: Solar chimney, natural ventilation, wire mesh screen.

\section{Introduction}

In our solar system, the sun, being at the center and supplying very large amount of energy, the total energy is emitted by the earth. This huge energy can be a valid suitable option for the source of future energy [1]. Malaysia is situated at the equatorial regions that allow Malaysia to receive very large amount of solar radiation throughout the year. It is found that monthly on an average solar radiation received by the Malaysian land is approximately $400-600 \mathrm{MJ} / \mathrm{m}^{2}$ and the average day light duration is approximately 4-8 hours per day. Malaysia is divided into two regions therefore the variation, the solar irradiation and light hours are too large. The magnitude of the solar radiation and light hour makes Malaysia a unique country in this reason that has plenty of solar energy for harvesting. It has very bright future as promising reliable backup source of sustainable energy. It can be a valid suitable option

Corresponding author: Md. Mizanur Rahman, Ph.D., Head Energy Research Unit (ERU), research fields: solar energy and water vortex. E-mail: mizanur@ums.edu.my. for generation electricity [2]. The solar chimney can be used for power generation as well as be house ventilation to ensure thermal comfort. The flow of air in the solar chimney occurs by natural convection process. It depends on the temperature difference between the solar collector and the ambient. The flow rate is also influenced by the physical parameter such as height, diameter, and air gap of the solar chimney [3-5]. The higher temperature difference between solar collector and ambient, causes the higher upward movement of the air in the chimney. Therefore, the aim of this paper is to estimate the ventilation effect or determine the change of air flow when different type wire mesh screen is installed in the solar chimney.

\section{Literature Review}

Solar chimney is a technology that is operated based on natural convection processes. In the solar chimney, the heat is absorbed by the heat absorber and the heat transfer process to the surrounding air occurs by natural convection. The heat transfer efficiency of solar absorber depends primarily on the geometry, intake air 
velocity and the temperature difference between process side and the ambient $[6,7]$. In the windy conditions, the chimney performance may drop more than $40 \%$ that affects the performance of the ventilation [8].

The natural convection concept universally applies to the free boundary flow phenomena of the column growth above high altitude land, forest fire and plume emitted from stacks [9-11]. The solar chimney starts function when the following happen:

- the process side temperature is higher than ambient temperature;

- the steady flow of hot air is in the upward direction from process side;

- the upward movement of air produces negative pressure at the air inlet of the heat exchanger;

- positive pressure is developed at the exit of the outlet of the heat exchanger;

- the hot air flows out through the chimney and cold air replaces the position of hot air from ambient. The flow reaches steady state when the solar absorber acts as a continuous heat source.

According to the Gan and Riffat in the year 1998 they explained that the main function of solar chimneys is to enhance the air movement in naturally ventilated building and the velocity of air through solar chimney is given by:

$$
v_{0}=\frac{\dot{V}}{A_{i}}=\sqrt{\frac{2 \Delta P_{t o t}}{\rho_{a}}}
$$

where, $\dot{V}$ is the volumetric flow rate $\left(\mathrm{m}^{3} / \mathrm{s}\right), A_{\mathrm{i}}$ is the inlet area $\left(\mathrm{m}^{2}\right), C_{\mathrm{d}}$ is the coefficient of discharge (dimensionless) which is directly proportional to flow resistance in the chimney and $\Delta P_{\text {tot }}$ is the total differential pressure $(\mathrm{Pa})$.

It is found that cross wind, hot air recirculation and cold inflow or flow reversal at exit of the solar chimney significantly weaken the efficiency of chimney and increase the exit pressure losses [3]. Andreozzi et al. [12] in the year 2010 have published a comprehensive review paper on the effects of cold inflow on some vertical geometry. The solar chimney performance drops significantly due to the draft loss. Study showed that the side wall can reduce the effect of the cross wind on solar chimney but cold inflow or flow reversal effects still exist in chimney as well as can be seen in solar chimney [13-15]. One of the valid and suitable suggestions given by $\mathrm{Chu}$ et al. [3] in 2012 is the wire mesh screen assisted chimney which can prevent the cold inflow significantly and restore the draft loss and enhance air flow rate in the chimney. The same concept is going to implement in the solar chimney ventilation system and determine the effect of wire mesh screen on solar chimney performance mainly in air flow rate.

\section{Methodology}

A solar model as shown in the Fig. 1 is designed and developed in the Energy Research Unit, Faculty of Engineering, Universiti Malaysia Sabah under the research grant FRG0429-TK-1/2015. The diameter and the height of the chimney was maintained $30 \mathrm{~cm}$. The natural convection process creates a very low velocity therefore convergent ducted which inlet diameter $10 \mathrm{~cm}$ is installed at the bottom of the chimney. The convergent duct helps to increase the velocity into measurable range. A $2.00 \mathrm{~kW}$ electric heating system is installed at the entrance of the chimney. The heating system is connected with a voltage regulator so that power can be varied from $0.25 \mathrm{~kW}$ to $1.00 \mathrm{~kW}$. At the beginning of the study, the wire mesh screens are installed at three different locations of the chimney model. The locations of the wire mesh screens are at the exit of the chimney, $5 \mathrm{~cm}$ above the heating system and at the inlet of the chimney model. It can be concluded from the preliminary experimental results that the wire mesh screen at the exit of the chimney can be used to increase the air flow rate in the chimney therefore the experiments were conducted in the solar chimney model with wire mesh screen at the exit. The $0.64 \mathrm{~mm}$ $\times 0.64 \mathrm{~mm}$ is used in the experiments. The wire mesh 


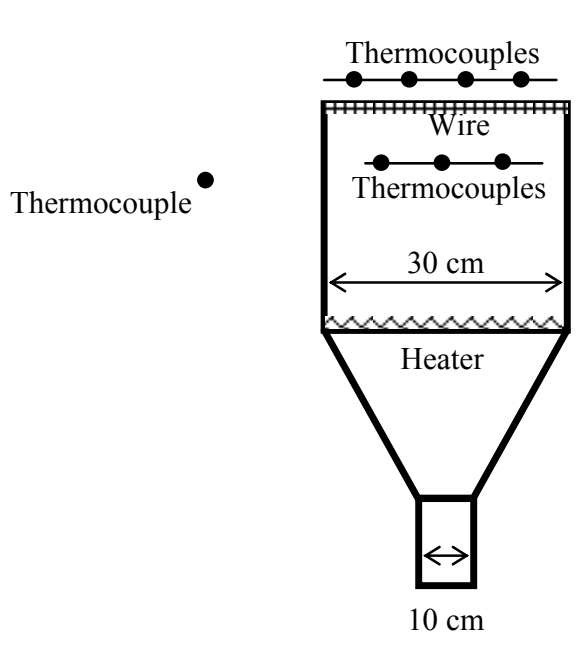

Fig. 1 Solar chimney model for laboratory.

screen is selected based on the availability in the local market. There are total eight thermocouples installed in the model chimney at the exit, just before the exit and outside as shown in Fig 1. All thermocouples are connected with computer through the data logger.

An automatic data acquisition system is used to extract the temperature data in every second as well as monitor each point directly. A vane type anemometer is installed at the entrance of the chimney model. A volt meter and a current meter are also installed in the system to measure the voltage and current during experiment.

\section{Experimental Procedure}

Experiments are conducted with and without wire mesh screen under different heat. The experimental procedure and flow in the experimental is shown in Fig. 2. The experiments start with initial heal load at approximately $0.25 \mathrm{~kW}$ and continue experiment for approximate value $0.5 \mathrm{~kW}$ and $1.0 \mathrm{~kW}$. The temperature, air velocity, voltage and current reading are started to record once the system reached into stable condition. The temperature data are recorded in 1 second interval whereas the air velocity, voltage and current reading are recorded with interval of $5 \mathrm{~min}$. All the experiments are repeated for wire mesh screen assisted solar chimney.

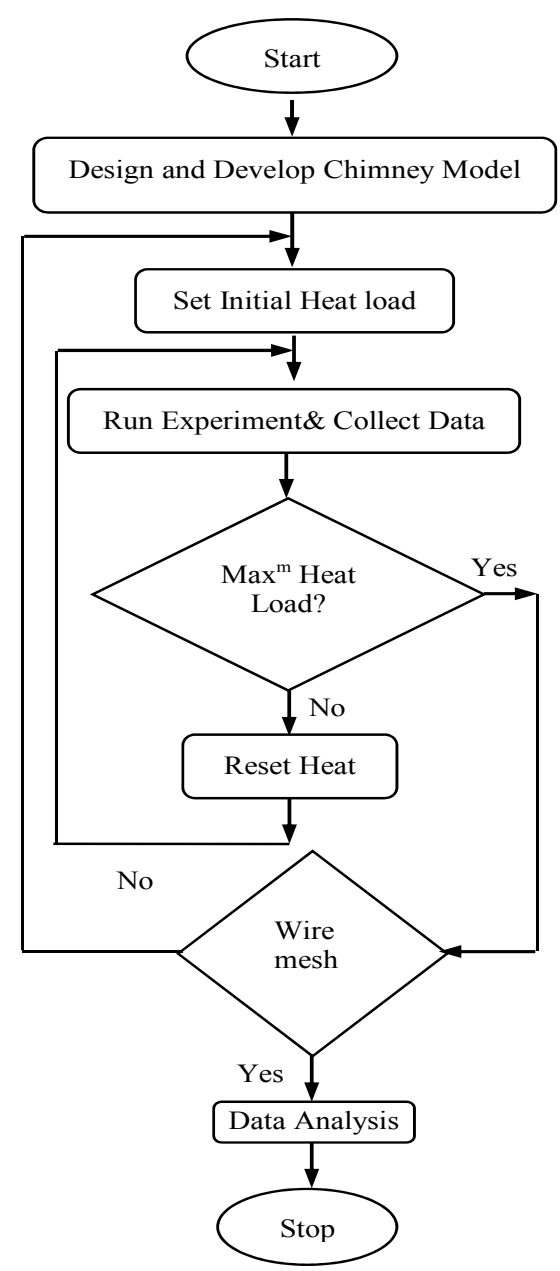

Fig. 2 Experimental procedure.

\section{Results and Discussion}

The velocities of air were measured in the same place at inlet of the chimney for different heat loads. The trends lines for the velocity at inlet represent the trends of flow rate at the chimney. The air flow rate in the normal chimney and wire mesh assisted chimney are shown in Fig. 3.

In Fig. 3, it is found that the maximum air velocity for the wire mesh screen assisted chimney had 0.56 $\mathrm{m} / \mathrm{s}$ where as in the normal chimney the magnitude has $0.46 \mathrm{~m} / \mathrm{s}$. In both cases the power ratings were almost same about $1,053 \mathrm{~W}$ and 1,055 W. The flow rate in the wire mesh assisted chimney is higher because of higher buoyancy effect. The chimney air temperatures are also measured and presented in Fig. 4. From the Fig. 4 it is found that the exit air temperature 


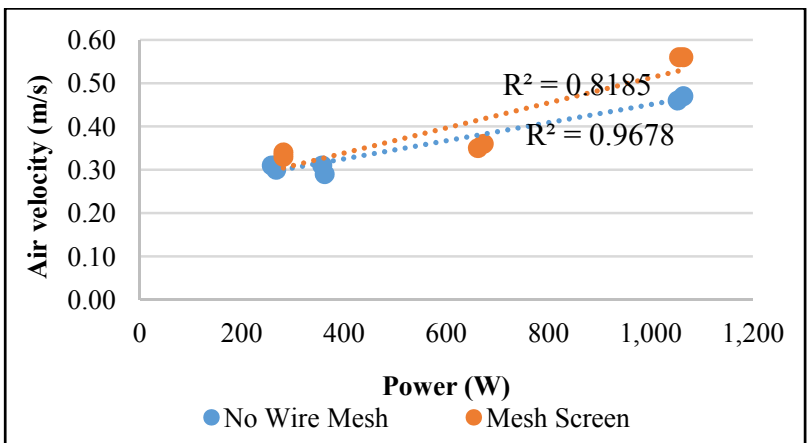

Fig. 3 Velocity comparison between wire mesh screens assisted chimney and normal chimney.

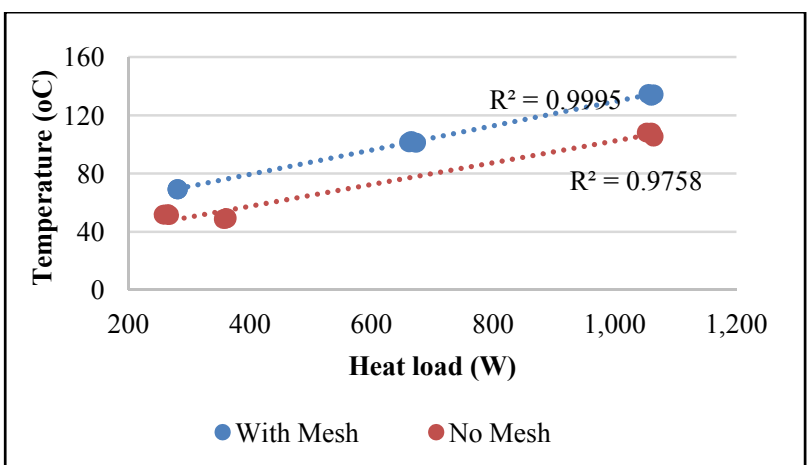

Fig. 4 Temperature comparison between wire mesh screens assisted chimney and normal chimney.

inside the solar chimney with mesh screen had high temperature vale compared to that without mesh screen. This is because of any of the following reason:

- In the mesh screen chimney the mesh screen initially reduced the flow rate so the air received more energy from the system. As a result the air temperature increased significantly. This higher temperature difference creates higher buoyancy effect and resulted in the enhanced flow rate.

- Mesh screen helps to protect the cold air inflow [3]. Cold in flow has significantly reduced the air flow rate and exit air temperature. Therefore cold inflow free operation of chimney has provide better output than normal chimney;

- The flow patterns before and after the wire mesh screen are different. When the fluid flows through the wire mesh, the flow started separated symmetrically around wire of the mesh screen. A wake is formed just immediately after the cylindrical wire which is considered pressure disturbance zone. The large eddies are also observed in this zone that occurs at a regular frequency. These eddies can produce an alternative life force that enhance the air flow rate at the chimney [16].

- Mesh screen could increase the heat received time or detention time or air so that enthalpy of air change, as a result, and the temperature of air and air velocity increased due to the change of internal energy [17].

- Wire mesh screen is able to restore the draft loss where all the air received more heat from the heat source [3].

\section{Conclusions}

The wire assisted chimney had shown better performance than traditional chimney. The wire mesh chimney had significantly improved the air flow rate and buoyancy due to the temperature difference between heating side and ambient. It can be concluded that wire mesh screen assisted chimney or solar chimney can be a suitable option for building ventilation. Since the wire mesh screen significantly improves the flow rate therefore, low height and bigger diameter chimney can be used for ventilation and power generation.

\section{Acknowledgements}

The authors would like to express gratitude thanks to the Ministry of Higher Education of Malaysia and Universiti Malaysia Sabah for their financial and facilities support through Fundamental Research Grant (FRG0429-TK-1/2015). Additionally, the authors would like to thank all the group members for their continuous support to complete this project.

\section{References}

[1] Robert, S. 2005. Energy Alternatives. Oxford: Heinemann Educational Publishers.

[2] Mekhilef, S., Safari, A., Mustaffa, W. E. S., Saidur, R., Omar, R., and Younis, M. A. A. 2012. "Solar Energy in Malaysia: Current State and Prospects." Renewable and Sustainable Energy Reviews 16: 386-96.

[3] Chu, C. M., Rahman, M. M., and Kumaresan, S. 2012. "Effect of Cold Inflow on Chimney Height of Natural Draft Cooling Towers." Nuclear Engineering and Design 249: 125-31.

[4] Zhou, X. J. Y. 2009. "Analysis of Chimney Height for 
Solar Chimney." Appl. Therm. Eng. 29: 178-85.

[5] Bernards, M. A., Vob, A., and Weinrebe, G. 2003. "Thermal and Technical Analyzes of Solar Chimneys." Solar Energy 75: 511-24.

[6] Chu, C. M. 2002. "A Preliminary Method for Estimating the Effective Plume Chimney Height above a Forced Draft Air Cooled Heat Exchanger Operating under Natural Convection." Heat Transfer Engineering 23: 3-12.

[7] Smrekar, J., Oman, J., and Sirok, B. 2006. "Improving the Efficiency of Natural Draft Cooling Towers." Energy Conversion and Management 47 (9-10): 1086-100.

[8] Zhai, Z., and Fu, S. 2006. "Improving Cooling Efficiency of Dry-Cooling Towers under Cross-Wind Conditions by Using Wind-Break Methods." Applied Thermal Engineering 26 (10): 1008-17.

[9] Afonso, C., and Oliveira, A. 2000. "Solar Chimneys: Simulation and Experiment." Energy and Buildings 32 (1): 71-9.

[10] Calcagni, B., Marsili, F., and Paroncini, M. 2005. "Natural Convective Heat Transfer in Square Enclosures Heated from Below." Applied Thermal Engineering 25 (16): 2522-31.

[11] De, A. K., and Dalal, A. 2006. "A Numerical Study of Natural Convection around a Square, Horizontal, Heated Cylinder Placed in an Enclosure." International Journal of Heat and Mass Transfer 49 (23-24): 4608-23.
[12] Andreozzi, A., Buonomo, B., and Manca, O. 2010. "Thermal and Fluid Dynamic Behaviors in Symmetrical Heated Channel-Chimney Systems." International Journal of Numerical Methods for Heat \& Fluid Flow 20 (7): 811-33.

[13] Kumaresan, S., Rahman, M. M., Chu, C. M., and Phang, H. K. 2013. "A Chimney of Low Height to Diameter Ratio for Solar Crops Dryer." In Developments in Sustainable Chemical and Bioprocess Technology. Boston, MA: Springer, 145-50.

[14] Phang, H. K., Chu, C. M., Kumaresan, S., Rahman, M. M., and Yasir, S. M. 2015. "Preliminary Study of Seaweed Drying under a Shade and in a Natural Draft Solar Dryer." International Journal of Science and Engineering 8 (1): $10-4$.

[15] Raghuvanshi, N. S., and Singh, A. 2014. "Development of Maintenance Strategy to Improve Performance of Natural Draft Cooling Tower." International Journal of Scientific and Research Publications 4 (8): 1-7.

[16] Qu, L., Norberg, C., Davidson, L., Peng, S. H., and Wang, F. 2013. "Quantitative Numerical Analysis of Flow Past a Circular Cylinder at Reynolds Number Between 50 and 200." Journal of Fluids and Structures 39: 347-70.

[17] Omojaro, A. P., and Aldabbagh, L. B. Y. 2010. "Experimental Performance of Single and Double Pass Solar Air Heater with Fins and Steel Wire Mesh as Absorber." Applied Energy 87 (12): 3759-65. 